OPEN ACCESS

Edited by:

Tom Crick,

Swansea University, United Kingdom

Reviewed by:

Dorian Gorgan,

Technical University of Cluj-Napoca,

Romania

Daniela Giordano,

University of Catania, Italy

*Correspondence:

llias O. Pappas

ilias.pappas@uia.no

Specialty section:

This article was submitted to

Digital Education,

a section of the journal

Frontiers in Education

Received: 13 January 2021

Accepted: 15 March 2021

Published: 09 April 2021

Citation:

Pappas 10 and Giannakos MN (2021) Rethinking Learning Design in IT Education During a Pandemic. Front. Educ. 6:652856. doi: 10.3389/feduc.2021.652856

\section{Rethinking Learning Design in IT Education During a Pandemic}

\author{
Ilias O. Pappas ${ }^{1,2 *}$ and Michail N. Giannakos ${ }^{2}$ \\ ${ }^{1}$ Department of Information Systems, University of Agder, Kristiansand, Norway, ${ }^{2}$ Department of Computer Science, \\ Norwegian University of Science and Technology, Trondheim, Norway
}

Maintaining high-quality teaching and learning in the times of a pandemic poses a huge challenge to education systems. To scaffold adequate practices in our courses during the pandemic, more advanced, and fine-grained "learning design" is needed than providing the learning objectives and learning materials of the course and defining the deliverables and assignments. In this paper, we leverage on our experience with putting into practice different learning designs and technologies, in various information technology (IT) contexts and discuss how IT educators can further reflect on the learning design of their courses and scaffold fully remote or blended learning approaches to accommodate their courses' needs during the pandemic. We provide three important objectives and indicative technological solution that can support those objectives, and discuss some lessons learned from our experience.

Keywords: learning analytics, learning design, learning spaces, pandemic, IT education, covid-19, IS education

\section{INTRODUCTION}

For information technology (IT) and information systems (IS) study programs have seen an enrollment increase in the past decade (Zweben and Bizot, 2015). This increase is driven from the growing demand for IT professionals in Europe (Smit et al., 2020), the United States (U.S. Bureau of Labor Statistics, 2020), as well as in other parts of the world. IT education requires skills spanning from both strong theoretical knowledge to diverse technical skills and competences. Such skills include leadership, project management, critical thinking, and change management (ACM/IEEE Joint Task Force, 2013), which are typically developed through real-world group-based project learning activities (Kolb, 2014; Pappas et al., 2018). Therefore, both traditional lecturestyle and project- or problem-based learning approaches are leveraged for the instruction of IT in higher education. Although there are several variances and the implementation of such approaches might slightly vary from one course to another and from one study program to another, they mainly rely, fully or partially, on face-to-face instruction and meetings, often supported with online communication and learning technologies.

Previous research on learning technologies and IT education has developed and practically demonstrated methods and tools for carrying out and supporting teaching and learning in online settings (Freeze et al., 2010; He et al., 2019). However, in practice, it is shown that during the pandemic, we were not prepared to put into practice fully remote learning and teaching (Daniel, 2020). Given that the current situation is likely to stay for some semesters, if not years, some can also argue that it is an opportunity for rethinking and reconsidering our practices to account for this 
acute need. Therefore, it is necessary to devise methods of education delivery for such situations, by taking into consideration students' needs, teachers' capacities, and the particularities of IT.

Learning design focuses on improving teaching quality by supporting practitioners along the process of scaffolding innovative and more effective learning situations (i.e., learning designs) (Lockyer et al., 2008). Learning design relies on various elements, in particular, it includes a set of learning activities (of different natures and granularity, from a single task to a course), includes a set of resources and tools that support the realization of the learning activities, it includes an instructional agent (e.g., teacher, the learners themselves) that supports the learner during the activities and sometimes provides feedback about the results and requires a certain degree of orchestration (e.g., management of the activities that learners undertake to attain the learning objectives, how the instructional agent supports the activities). Learning design is critical for improving teaching quality, innovating learning practices, and adapting to disruptions and contextual changes (Bennett et al., 2017).

Building upon existing technologies and practices such as mentoring via video meetings, assignments, peer- and self- assessment, clickers and team projects, we portray how scaffolding important elements of the learning design can allow us to mimic some of the face-to-face interactions and rectify students' learning experience. This position is mainly grounded on experiences and related works coming from the field of IT education and primarily caters to support researchers and practitioners developing courses in this field. We also acknowledge that some of the lessons learned and the presented technologies, will also support researchers and practitioners outside the IT education space. Therefore, this paper aims to provide a springboard for IT researchers and practitioners to reflect on the learning design of their courses and the opportunities offered by learning technologies and analytics to scaffold fully virtual or blended learning approaches that accommodate their courses' needs, meet learning objectives, and maintain students' high learning experience (e.g., motivation, engagement).

\section{LEARNING SPACES IN IT EDUCATION DURING A PANDEMIC}

Information technology and IS curricula [as depicted from IS2010 (Topi et al., 2010), MSIS 2016 (Topi et al., 2017), ACM/IEEE (ACM/IEEE Joint Task Force, 2013), and other IT related curricula ${ }^{1}$ ] cover competences typically associated with systems analysis and design and project management, data(base) management, IT infrastructure; and IT policy, strategy, and management. IT competencies and skills that are most in demand from employers, include technical skills such as programming skills, web development, data visualization and cybersecurity; and soft skills such as critical thinking, complex problem

${ }^{1} \mathrm{ACM}$, IEEE and AIS, IT related curricula recommendations: https://www.acm. org/education/curricula-recommendations solving, creativity and decision-making (Pan and Seow, 2016; Burns et al., 2018). Typically, IT study programs offer courses covering most these competences and skills, leveraging on various teaching and learning spaces (e.g., classrooms, meeting rooms, the industry) and physical and digital resources (e.g., videos, lecture slides).

The learning space is where teaching or learning is happening and where different types of processes are conducted along with different interrelationships among students, educators, and the various resources (Giannakos et al., 2016). Therefore, it is important to consider the digital and physical resources (e.g., slides, lecture recordings, blog entries, books, notes, and handicrafts), along with the interactions between the main actors (students and educators), between the main actors and the resources (content), as well as between the resources themselves (e.g., recommender systems) (Anderson, 2003). Such interactions shape the quality and value of students' learning experience, and are the ones damaged most in a crisis period such as the pandemic. Our ability to develop teaching approaches enhancing students' dynamics and needs is critical, especially during the pandemic.

During the pandemic the learning space has become fully digital including the same learning resources. While learning space is transforming, we also need to rethink about the other qualities of the learning design in IT education and proceed with potential adjustments. Traditional learning activities in IT courses include lectures, project-work individual assignments and engagement with other learning materials (e.g., self-reading, self-assessment). Such material can also be interactive in nature, such as video-assignments or interactive exercises (Pappas et al., 2017), allowing the instructor to assure that students will access the content and attain the necessary knowledge (e.g., fundamental knowledge about programming, IT policy, and management). Such autonomy in learning is typical in many active learning approaches (e.g., flipped classroom), where students are involved with the learning material in order to obtain the initial fundamental knowledge. This self-regulated, but also well-defined approach, allows students to engage with the content and reflect about their learning with the various IT concepts (Giannakos et al., 2016).

To reinforce awareness, reflection and self-regulation, contemporary learning design practices combine basic e-learning tools and traditional learning practices. For example, educators prepare short videos with learning materials that offer the students the opportunity to obtain the initial fundamental knowledge (Pappas et al., 2017). Such video lectures can be combined with quizzes or exercises, thus reinforcing selfassessment and self-regulated learning (Kizilcec et al., 2017). Typical quizzes can also be employed through the traditional learning management systems (LMSs) such as Canvas and BlackBoard, where students can take them any time, before or during the course. However, gamifying quizzes and employing them during the instruction has shown that it can lead to increased student motivation, engagement, enjoyment, and concentration (Giannakos et al., 2015; Wang, 2015; Zainuddin et al., 2020). Those positive effects are connected with the social interactions that are nurtured with many of these technologies 
(e.g., Kahoot!), which are reaching their potential when put into practice in live during the instruction (Wang and Tahir, 2020).

Another element that has always been critical in higher education is academic integrity. Academic integrity is becoming even more critical during the pandemic (Blankenberger and Williams, 2020), and it is great responsibility of colleges, universities and educators in safeguarding. In online environments, it is important to deal with the issue of verifying student identity, as needed, while keeping academic integrity. The International Center for Academic Integrity (ICAI) enumerates five fundamental values-honesty, trust, fairness, respect, and responsibility [International Center for Academic Integrity (ICAI), 2021]. Academic integrity is necessary to exist for both teachers and students to successfully accomplish the learning objectives in higher education, with studies examining how teachers, administrators, and students can develop a common understanding of the different dimensions of academic integrity (Manly et al., 2015), especially in the times of a pandemic (Guangul et al., 2020; Lancaster and Cotarlan, 2021). Within a regular LMS, students have unique IDs used for assessing various assignments that are submitted in a course throughout the semester. When using a clicker the students can use pseudonyms which can be mapped by the teacher privately, through the LMS, in order to verify student identity. Real-time response systems, like clickers, may reduce students' chances of cheating as the time to respond to a question is limited and there is no option to go back to a question. Offering limited time to respond is also common practice in traditional quizzes. These ways of identity verification are applicable in course with both small and very large number of students. Given the nature of IT education (e.g., heavily relying in projects and assignments), academic integrity has been a major research topic. A range of strategies and approaches has been adopted by researchers and practitioners, with related work highlighting the importance of students' trust in the academic integrity of the learning environment, as well as the need for initiatives that educate and empower students' to comply with the respective policy (Sheard et al., 2017). The issue of academic integrity and verification becomes even more important during the examination or when the assessment is connected with the final grade of the student. The strategies mentioned in the literature is a good starting point and can be combined; with focusing on educating, discouraging and preventing students from cheating being the most common ones in IT education [e.g., proper introduction to integrity, making cheating difficult, see more from Sheard et al. (2017)].

The assessment of the IT courses was typically done through exams, with some exceptions (e.g., full project-based course, or portfolio assessment course). This has also partially transformed during the pandemic with certain advantages and disadvantages, such as changing to online exams (Chirumamilla et al., 2020), shifting the grading protocols from point-based to pass/fail, or adopting live proctoring (Barker et al., 2020; Kharbat and Abu Daabes, 2021) techniques. Despite the proper policies and measures (i.e., academic integrity), this transition has resulted in making cheating easier, with both students and teachers perceiving cheating to be significantly easier with e-exams, and especially with the use of third devices (Chirumamilla et al., 2020). Nonetheless, this position paper is focusing on learning design and assessment during the semester, with the more traditional "end of semester examination" being somehow beyond the scope of this paper.

Another important benefit of the introduction of digital resources to the instruction is that students' interaction with such resources produces useful learning analytics that allow instructors to gain insights about their students' progress (Giannakos et al., 2015; Vesin et al., 2018). The instructors can "sense" students' progress and, tailor their teaching practices and modify their learning design accordingly. Such evidence-based insights allow the instructor to obtain some of the insights they normally collect during the face-to-face instruction and to be well-prepared for the live sessions (either virtual or physical), by addressing potential misunderstandings and misconceptions of the students (Jovanović et al., 2017; Pappas et al., 2017).

In both online and blended conditions, for efficient learning, strong self-regulated learning skills and good self-assessment and awareness mechanisms are required (Broadbent, 2017). Adaptive learning environments can address personalized learning needs through adaptive content/activities (Premlatha and Geetha, 2015), as group or individualized recommendations (Chen et al., 2018), as analytics dashboards and open learner models (Bodily et al., 2018), or by adjusting learning design to meet learners' abilities (Towle and Halm, 2005). Adaptive self-assessment and feedback mechanisms, which are increasingly becoming available to teachers, can reinforce students' learning in critical periods where direct feedback via face-to-face physical instruction is not possible and, at the same time, keep students' motivated and engaged (Papamitsiou et al., 2021). The challenge is to leverage these capabilities offered by time-tested learning technologies and analytics to support the learning design of our courses (Table 1 provides examples) and remedy the challenges imposed on our education systems due to the pandemic.

\section{USER ANALYTICS-ENABLED TECHNOLOGIES IN A TYPICAL IT COURSE}

Various analytics-enabled technologies exist and are applied in different learning practices in IT education (Grover and Korhonen, 2017a; Korhonen and Grover, 2018). As the learning space became almost fully digital during the pandemic crisis, digital-footprints of the learning activity (i.e., learning analytics) increase and enable better orchestration and management of the teaching and learning process. During the last years, there is an increasing interest in learning analytics in IT education, by focusing not only on awareness and reflection (what has been happening in the past) but also on predictions of students behavior in the future and offering the needed guidance to support better learning trajectories (Grover and Korhonen, 2017b).

During the outbreak of Covid-19, several of the aforementioned learning activities were implemented in an IS course that was designed before the pandemic, but had to adopt its activities during the pandemic. Typically, an LMS 
TABLE 1 | Objectives, technology, and indicative case studies from the literature.

\begin{tabular}{|c|c|c|}
\hline Objective & Technology & Source \\
\hline $\begin{array}{l}\text { Enhance interaction and } \\
\text { assess students' } \\
\text { understanding. }\end{array}$ & $\begin{array}{l}\text { Real-time response system } \\
\text { (e.g., Kahoot). }\end{array}$ & Wang, 2015 \\
\hline $\begin{array}{l}\text { Increase student } \\
\text { awareness and reflection } \\
\text { through self-assessment. }\end{array}$ & $\begin{array}{l}\text { Adaptive self-assessment } \\
\text { (e.g., SmartU). Regular } \\
\text { self-assessment systems } \\
\text { (e.g., Canvas, Blackboard). }\end{array}$ & $\begin{array}{l}\text { Papamitsiou et al., } \\
2021\end{array}$ \\
\hline $\begin{array}{l}\text { Providing tailored content } \\
\text { to students based on } \\
\text { their experience and } \\
\text { mastery level. }\end{array}$ & $\begin{array}{l}\text { Adaptive } \\
\text { content/recommendation } \\
\text { systems (e.g., ProTus). }\end{array}$ & $\begin{array}{l}\text { Vesin et al., 2018; Vesin } \\
\text { et al., } 2021\end{array}$ \\
\hline $\begin{array}{l}\text { Coupling learning } \\
\text { materials with } \\
\text { assessment. }\end{array}$ & $\begin{array}{l}\text { Video based assessment } \\
\text { (with video assignment). }\end{array}$ & Pappas et al., 2017 \\
\hline \multirow[t]{2}{*}{$\begin{array}{l}\text { Collecting learning } \\
\text { analytics to support } \\
\text { teaching and learning. }\end{array}$} & $\begin{array}{l}\text { Video learning analytics } \\
\text { allow students and } \\
\text { teachers to track which } \\
\text { video lectures they have } \\
\text { studied and help them } \\
\text { navigating thought the } \\
\text { video materials. }\end{array}$ & Giannakos et al., 2015 \\
\hline & $\begin{array}{l}\text { Dashboards allow students } \\
\text { and teachers to monitor } \\
\text { their course progress (e.g., } \\
\text { Mastery Grids). }\end{array}$ & Guerra et al., 2016 \\
\hline $\begin{array}{l}\text { Enhance collaboration } \\
\text { and learning, and direct } \\
\text { interaction and feedback. }\end{array}$ & $\begin{array}{l}\text { Virtual Breakout rooms } \\
\text { (e.g., Zoom, Blackboard). }\end{array}$ & $\begin{array}{l}\text { Chandler, } 2016 \text { Li } \\
\text { et al., } 2021\end{array}$ \\
\hline $\begin{array}{l}\text { Automatize the } \\
\text { production of learning } \\
\text { content to support } \\
\text { instructors. }\end{array}$ & $\begin{array}{l}\text { Eases the production, } \\
\text { management and } \\
\text { publication of video lectures } \\
\text { (e.g., Panopto) }\end{array}$ & Arnold, 2019 \\
\hline
\end{tabular}

(e.g., Canvas) is used to orchestrate course material, digital communication, assignments, and project work. In the course we prepared short videos (5-8 min duration) with fundamental concepts from the different modules of the course (three videos per module), typical in flipped classroom settings. The videos were designed to be made available a week before the topic was discussed in class. Each set of videos was accompanied with an online quiz consisting of different types of questions (multiple choice, true/false, open ended, put in the correct order). The quiz was given to the students during the class, as formative assessment, for student evaluation and feedback.

For the quizzes, a real-time response system (i.e., Kahoot!) and a regular LMS (i.e., Canvas) were employed. The two tools offer complementary affordances to support the learning experience. The Kahoot! allowed for increased interaction and sociability during the class, while each question was triggering a discussion after all responses were recorded. This allows the instructor to activate students (since they had to participate to Kahoot!) and identify potential misunderstandings and misconceptions. In addition, this makes it easier for the student to ask clarifying questions and engage to a constructive argumentation and negotiation with the teacher. To increase engagement and participation each quiz counted toward the grade. Quizzes via clickers can be performed either physically in class or online (e.g., via Zoom or Microsoft Teams), where the teacher simply shares their screen with the class. A main difference from taking a quiz online compared to physically is that the students cannot discuss with each other before answering or after they have answered. However, a gamified quiz makes students more active, while informing the teacher about their understanding of fundamental concepts through the formative assessment. It creates the sense of sociability since students see others' scores and progress, which in turn allows the lecturer to identify and discuss difficult concepts. When using Canvas (or any other LMS) for the quiz, each student takes the quiz in silos which leads to reduced social interaction during the quiz. Depending on the type of questions, such a quiz can be used in group-work sessions to start a discussion and reflect on the content. Such group-work can be done both offline and online, such as by using the breakout rooms on Zoom. Providing a combination of such quizzes increases the variety of resources and content given to the students leading to increased satisfaction, as mentioned during the mid-term evaluation of the course.

Sometimes it is important for the teacher to be able to verify students' identity during the quiz (e.g., when their quiz performance counts toward the final grade, or for the teachers to be able to follow students' progress/misconceptions). When the quiz is employed through the typical LMS of the university, such verification is happening through the formal login functionality. When the quiz is employed through a clicker's device, to retain anonymity the teacher can ask students to use pseudonyms. Then, we asked the students to report their pseudonyms to the teacher and made a mapping between pseudonyms and real names that was stored in the regular LMS, available only to the teacher. The students were asked to use the same pseudonym in all quizzes to facilitate the process. We rely on systems that the individual student has unique access, and there is certain degree of responsibility from the student, similar to the one when a student submits an assignment or a project in the prepandemic times. Considering that quizzes do not run under exam conditions, this should be an acceptable practice, as it allows us to confirm student identity (with the use of an agreed pseudonym), while at the same time we do not require access to other personal information that may increase privacy risks or be more invasive (e.g., identity verification via live video). Nevertheless, we also recognize that for examination purposes, different principles and technologies are necessary.

When the "traditional" classroom pedagogies were transformed to digital, the typical lecture became either a prerecorded video lecture or a live webinar. In any case, after the live or pre-recorded video lecture the students had a short period for interaction with the instructor (e.g., $20 \mathrm{~min}$ ) to discuss some of the concepts, clarify potential questions or engage to a digital learning activity (e.g., taking a quiz or solving an exercise). Such sessions were almost always recorded and shared with the students for post-reading. While most of the materials can be accessed by the students before or after the live session, students' participation during the live session is of paramount importance since it (1) creates a more direct and personal experience for both the students and teacher; (2) helps students to stay on track and keep a routine similar to the one before the pandemic; and 
(3) allows the instructor to interact with the students, bring them up to speed, "sense" their progress and adjust the learning design, when necessary.

To further enhance collaborative learning and leverage on direct interaction and feedback a peer review session was organized. First, students were organized into groups by the teacher and each group was instructed to review assignments from another group. This was another form to reinforce feedback and enable discussion which was moderated and facilitated by the teacher. Next, the groups held short presentations of their projects by sharing their screen, or a prerecorded video, and then the preassigned group would give feedback and discuss. This process attempted to mimic traditional instruction and remedy the limitations imposed from the pandemic; our observations depict that it was possible for the students to generate new ideas as well as focus on specific issues in order to solve a problem or to offer solutions during these sessions. While the lack of physical presence hindered students' motivation; concrete description of the process and proper scaffolding, such as clear templates, expectations and a process (e.g., create their own virtual rooms, in dedicated time slots, during which the teachers and the assistants would visit to give direct feedback, answer questions, and solve any issues related to the students' project work) allowed students to engage to constructive interaction with their peers and the teaching assistants.

\section{TECHNOLOGICAL SOLUTIONS TO SUPPORT THE LEARNING DESIGN DURING THE PANDEMIC}

In this position paper we discuss how IT/IS educators can support the learning design of their courses during the pandemic. The evidence for this paper comes from our experience with putting into practice different learning designs and technologies and in particular, from a typical IT course that employs a mix of assessment methods, in which a large part of the grade is based on a project (common in IT courses). To strengthen the evidence and support our discussion, we are also providing evidence coming from the IT education literature. Our experience as well as the indicative case studies from the literature is connected with the challenges of IT education in particular, but many of them are relevant for other educational domains. Considering the benefits of technology in rectifying students experience and supporting the learning design, the following three pillars can serve as a baseline.

\section{Enhancing Interaction and Collaboration}

One of the objectives we have discussed the most, concerns how to enhance interaction and motivation during remote teaching and learning. The use of real-time response systems allow students to interact with the teacher and participate to socially engaging activities (Wang, 2015). Along the same lines, teachers need to be able to enhance collaboration between the students and give them meaningful feedback. In most of the cases, this happens though the use of a video conferencing system and the use of break out rooms (Chandler, 2016; Li et al., 2021).

\section{Supporting Teachers}

The challenges as well as expectations requested from the teachers, during the pandemic have dramatically increased. The need to produce new digital learning resources and familiarize ourselves with the various learning technologies is a time demanding and sometimes challenging task. New tools such as Kaltura and Panopto allow teachers to produce, manage, publish, and analyze learning videos professionally, with minimal effort (Arnold, 2019). In addition to the use of content production systems, teachers are also equipped with certain learning analytics functionalities. For instance, knowing which learning materials have been accessed from students and the extend they have watched the provided video lectures, can allow teachers to adapt their instruction and learning design accordingly (Giannakos et al., 2015; Guerra et al., 2016).

\section{Personalized and Smart Learning Content and Assessment}

During the last years, we have seen several efforts in developing an adaptive learning environment that provides personalized learning and assessment to students (Papamitsiou et al., 2021; Vesin et al., 2021). Such systems provide tailored content to students based on their experience and mastery level, and allow them to engage with personalized self-assessment. Engaging in such activities, help students to increase their self-regulation and motivation about the course (Duffy and Azevedo, 2015).

The following table synopsizes the various objectives, technologies and indicative examples from the literature.

\section{LESSONS LEARNED AND THE WAY AHEAD}

Educational disruptions (e.g., due to students' low self-esteem, unsupportive teachers, crises such as the Covid-19 pandemic) may result in demotivating learners with overall unwanted consequences for their learning. To deal with such disruptions we need to rethink and revise the learning design of our course and leverage on analytics-enabled technologies that allow us to mimic physical learning experiences or construct novel ones that have the capacity to remedy the challenges imposed on our education systems due to the pandemic. Current needs in education point to directions that are different from the ones reflected in the pre-Covid era. Some of the major differences are related to the following topics and we offer the following suggestions to improve learning designs. Table 2 summarizes the lessons learned.

\section{Student-Centered Learning Design That Accounts for the Needs Imposed From the Pandemic}

Teachers can revise existing material without spending an extensive effort to develop brand new. Reusing material (e.g., multiple choice questions) that can be "modernized" and offered in a more direct, enjoyable (e.g., gamified quiz) or personalized way (e.g., adaptive learning and self-assessment) can be more 
TABLE 2 | Lessons learned.

1 Student-centered learning design that accounts for the needs imposed from the pandemic.

2 Automatize learning content to support teachers and address pedagogical preparedness.

3 Fine-grained scaffolding of the learning spaces and activities.

4 Proper transformation of critical parts of the course, with a focus on enabling feedback and assessment.

5 Empowering the social component of learning through collaborative learning and mimicking of physical learning.

6 The increased importance of students' privacy and academic integrity.

efficient for the students, while not significantly increasing the workload for the instructor. Also, we suggest reducing the typical 2-3 h lecture to smaller in duration, but more focused live sessions (e.g., 15-20 $\mathrm{min}$ ). These sessions should include time for interaction with the teacher but also activities that engage the students (e.g., quizzes, challenges). Further, designing for students to work in teams and on case studies (on data science applications) through dedicated virtual environments (e.g., Zoom break out rooms) allowed them to benefit and generate value directly relevant for their post graduate life. It is important to remember that on each lecture the main goals of the session and the exercises need to be communicated to the students to help them understand the goal, thus keeping them more active during the session. The instructor can create online materials (e.g., videos) that are directly connected to the live activities and potential assignments and catalog them properly (e.g., up to $5 \mathrm{~min}$ for different topics). These videos need to be given to the students every week or two to allow them to interact with those videos and use them to reinforce the live sessions. Videos provided from the instructor need to be more personal to the students compared to available online videos, addressing specific challenges and misconceptions raised during the live sessions. The development of such videos might result in extra workload for the instructor; however, such videos do not need professional editing or equipment and can be used for more than 1 year.

\section{Automatize Learning Content to Support Teachers and Address Pedagogical Preparedness}

The limited resources combined with the need for emergency responses regarding teaching during the pandemic, challenged teachers' preparedness at different levels. To address this issue, we propose the use of systems that automatize the learning content creation, such as in offering easy to use solutions for producing, editing, and storing new material or video-based lectures. Current solutions (e.g., Kaltura, Panopto) allow to create recordings from the computer or from classrooms, and upload and edit already recorded videos. Such tools allow the integration of quizzes within the videos, which can help in engaging student attention. Our experience shows that editing videos can be a challenging part as it requires a certain amount of time to trim the videos, merging parts from different videos, as well as controlling which source (e.g., slide, document, and camera) the student sees at any given time. These tools allow to perform such tasks without the need for advanced skills on video creation and editing and support the whole process of producing, editing and using the video with single software. Further, automatic recording and streaming of classroom teaching from auditoriums can reduce teachers' overload, as once a lecture is logged in the time plan, the recording and streaming start automatically, while the teacher only needs to wear a microphone and start the lecture. The students find recordings very useful, as it alleviates any potential network issues since they are able to access the lecture at any point later in time. However, this may have some unwanted effects, as the students may choose not to participate to a lecture if they know they will have access to it via a recording. To address this issue, we suggest employing interactive tools in class (e.g., quizzes) and design discussion sessions within the lecture, that allow students to see the value of participation, despite the fact that the video lecture will be available on-demand.

\section{Fine-Grained Scaffolding of the Learning Spaces and Activities}

Due to the limitations from the absence of the physical communication, it is important that the learning activities and preparation of the digital spaces is well thought. Therefore, it is important that the students have predefined online meeting rooms in environments that support the needed functionalities (e.g., Zoom for webinar lecturing, Discord for laboratory exercises for 1-1 interaction) in specific slots during the week, in which the instructor is able to visit them to answer questions and give feedback. Such grouping can be modeled after the regular teamwork sessions that students held physically or predefined based on a specific process, expectations or even randomly. When the students are aware that the teacher would visit their group, they are more likely to be active and have some progress to report. Moreover, students were asked to create (or update) group "contracts" with their team as cooperation agreements, stating basic rules on their cooperation but also on what should happen when members of the team did not follow the rules. This allows the creation of contingency plans for the teams and smooth progression that, sometimes, encounters communication challenges due to the lack of physical meetings and non-verbal communication.

\section{Proper Transformation of Critical Parts of the Course, With a Focus on Enabling Feedback and Assessment}

E-portfolios, project work and dossier assessment are widely employed in IT education. The courses we offered were also project-based and the assessment was done in a final deliverable. The students delivered updated versions of their reports (using track changes) to receive feedback in short online sessions every 2 weeks in an agile manner. This led to fewer lectures and more feedback sessions with each group throughout the semester. Feedback was also given via recordings that combined videos and annotations on the reports. This extended feedback provided was appreciated by the students and was also used for reflection at the end of the project. 


\section{Empowering the Social Component of Learning Through Collaborative Learning and Mimicking of Physical Learning}

The social component of learning is the one that has been damaged the most in these first months of the pandemic. Therefore, it is important that the learning design includes events, data, and information that reinforces the sociability in the learning situation. Mimicking physical meeting with properly scaffolded live sessions and scaffolding sessions (e.g., peerassessment) that enable rich interaction and feedback allowed students to experience (at least partly) the social component of a physical course.

\section{The Increased Importance of Students' Privacy and Academic Integrity}

The importance of academic integrity is even more important during the pandemic, it has always been an important research topic in IT education (ref, ITIcse), but due to the transformation of fully remote teaching and online examination, the role of academic integrity is critical. Due to this transformation, students' are obliged to use several digital learning technologies significantly more, and this can lead to data privacy concerns, particularly with regards to transparency, accountability, fairness, and bias aspects of students' data. The EU's General Data Protection Regulations (GDPR) provides a general frame for any research and practice that includes human-factors. Therefore, it is important for faculty members to familiarize themselves with those routines and making sure that all the needed practices take place (e.g., written consent forms whenever are needed) and that they employ the needed privacy-preserving methods, as well as they select and use the various technologies in a way that is transparent and respects students' rights (e.g., technologies that have signed data-processing agreements with their institute).

\section{REFERENCES}

ACM/IEEE Joint Task Force (2013). Computer Science Curricula 2013: Curriculum Guidelines for Undergraduate Degree Programs in Computer Science. Technical report. New York, NY: Association for Computing Machinery (ACM) IEEE Computer Society.

Anderson, T. (2003). "Modes of interaction in distance education: recent developments and research questions," in Handbook of Distance Education, ed. M. Moore (Mahwah, NJ: Erlbaum), 129-144.

Arnold, S. (2019). "Flipping the lecture: students demonstrate learning with the panopto video capture system," in Proceedings of the Society for Information Technology \& Teacher Education International Conference, Barcelona.

Barker, S., Suri, H., Gregory, B., Warner, A., White, A., Venkiteswaran, V., et al. (2020). "Learning from COVID-19 to futureproof assessment in Business Education," in Proceedings of the Australasian Society for Computers in Learning in Tertiary Education (ASCILTE), Virtual Conference.

Bennett, S., Agostinho, S., and Lockyer, L. (2017). The process of designing for learning: understanding university teachers' design work. Educ. Technol. Res. Dev. 65, 125-145. doi: 10.1007/s11423-016-9469-y

Blankenberger, B., and Williams, A. M. (2020). COVID and the impact on higher education: the essential role of integrity and accountability. Admin. Theor. Praxis 42, 404-423. doi: 10.1080/10841806.2020.177 1907

Bodily, R., Kay, J., Aleven, V., Jivet, I., Davis, D., Xhakaj, F., et al. (2018). “Open learner models and learning analytics dashboards: a systematic review," in
While making these suggestions, faculty members face an increased workload, especially since they need to work with new systems, routines and sometimes even develop new learning materials. This directs toward a re-balancing and prioritization of certain changes, which can be facilitated through technologies that offer automated support and enable the implementation of assessment techniques. Such technologies also allow us to modernize existing materials (e.g., multiple choice questions) but also increase students' self-regulation and motivation, and provide us with analytics about their progress and misconceptions. For effective coordination to happen within a learning ecosystem we need existing mechanisms to support teachers and learners during crises such as a pandemic, and empowering to see themselves as learning designers that are reflective and embrace and account for students' feedback (e.g., via learning analytics, evaluation forms, oral). This paper discusses practices and technologies for responding effectively to today's circumstances, and planning systematically for the unforeseeable future in the post-pandemic era, leading to a Covid-compliant transformation for our education system.

\section{DATA AVAILABILITY STATEMENT}

The original contributions presented in the study are included in the article/supplementary material, further inquiries can be directed to the corresponding author/s.

\section{AUTHOR CONTRIBUTIONS}

Both authors listed have made an equal, substantial, direct and intellectual contribution to the work, and approved it for publication.

Proceedings of the 8th International Conference on Learning Analytics and Knowledge, Sydney, NSW.

Broadbent, J. (2017). Comparing online and blended learner's self-regulated learning strategies and academic performance. Internet Higher Educ. 33, 24-32. doi: 10.1016/j.iheduc.2017.01.004

Burns, T., Gao, Y., Sherman, C., and Klein, S. (2018). Do the knowledge and skills required by employers of recent graduates of undergraduate information systems programs match the current ACM/AIS information systems curriculum guidelines? Inform. Syst. Educ. J. 16:56.

Chandler, K. (2016). Using breakout rooms in synchronous online tutorials. J. Perspect. Appl. Academic Pract. 4, 16-23.

Chen, Y., Li, X., Liu, J., and Ying, Z. (2018). Recommendation system for adaptive learning. Appl. Psychol. Meas. 42, 24-41.

Chirumamilla, A., Sindre, G., and Nguyen-Duc, A. (2020). Cheating in e-exams and paper exams: the perceptions of engineering students and teachers in Norway. Assess. Eval. High. Educ. 45, 940-957. doi: 10.1080/02602938.2020.1719975

Daniel, S. J. (2020). Education and the COVID-19 pandemic. Prospects 49, 91-96.

Duffy, M. C., and Azevedo, R. (2015). Motivation matters: interactions between achievement goals and agent scaffolding for self-regulated learning within an intelligent tutoring system. Comput. Human Behav. 52, 338-348. doi: 10.1016/ j.chb.2015.05.041

Freeze, R. D., Alshare, K. A., Lane, P. L., and Wen, H. J. (2010). IS success model in e-learning context based on students' perceptions. J. Inform. Syst. Educ. 21:4.

Giannakos, M., Chorianopoulos, K., and Chrisochoides, N. (2015). Making sense of video analytics: lessons learned from clickstream interactions, attitudes, and 
learning outcome in a video-assisted course. Int. Rev. Res. Open Distributed Learn. 16, 260-283.

Giannakos, M. N., Krogstie, J., and Aalberg, T. (2016). Video-based learning ecosystem to support active learning: application to an introductory computer science course. Smart Learn. Environ. 3:11.

Grover, S., and Korhonen, A. (2017a). Special issue on learning analytics. ACM Trans. Comput. Education Educ. 17.

Grover, S., and Korhonen, A. (2017b). Unlocking the potential of learning analytics in computing education. ACM Trans. Comput. Education Educ. 17.

Guangul, F. M., Suhail, A. H., Khalit, M. I., and Khidhir, B. A. (2020). Challenges of remote assessment in higher education in the context of COVID-19: a case study of Middle East College. Educ. Asse. Eval. Acc. 32, 519-535. doi: 10.1007/ s11092-020-09340-w

Guerra, J., Hosseini, R., Somyurek, S., and Brusilovsky, P. (2016). “An intelligent interface for learning content: combining an open learner model and social comparison to support self-regulated learning and engagement," in Proceedings of the 21st International Conference on Intelligent User Interfaces, Sonoma, CA.

$\mathrm{He}$, W., Xu, G., and Kruck, S. E. (2019). Online IS education for the 21st century. J. Inform. Syst. Educ. 25, 101-105.

International Center for Academic Integrity (ICAI) (2021). The Fundamental Values of Academic Integrity, 3rd Edn. Available online at: www.academicintegrity.org/the-fundamental-values-of-academic-integrity (accessed February 15, 2021).

Jovanović, J., Gašević, D., Dawson, S., Pardo, A., and Mirriahi, N. (2017). Learning analytics to unveil learning strategies in a flipped classroom. Internet Higher Educ. 33, 74-85. doi: 10.1016/j.iheduc.2017.02.001

Kharbat, F. F., and Abu Daabes, A. S. (2021). E-proctored exams during the COVID-19 pandemic: a close understanding. Educ. Inform. Technol. 1-17. doi: 10.1007/s10639-021-10458-7 [Epub ahead of print].

Kizilcec, R. F., Pérez-Sanagustín, M., and Maldonado, J. J. (2017). Self-regulated learning strategies predict learner behavior and goal attainment in Massive Open Online Courses. Comput. Educ. 104, 18-33. doi: 10.1016/j.compedu. 2016.10.001

Kolb, D. A. (2014). Experiential Learning: Experience as the Source of Learning and Development. Upper Saddle River, NJ: FT press.

Korhonen, A., and Grover, S. (2018). "Special issue on learning analytics and regular papers," in ACM Transactions on Computing Education (TOCE), 18.

Lancaster, T., and Cotarlan, C. (2021). Contract cheating by STEM students through a file sharing website: a Covid-19 pandemic perspective. Int. J. Educ. Integrity $17,1-16$

Li, L., Xu, L. D., He, Y., He, W., Pribesh, S., Watson, S. M., et al. (2021) Facilitating online learning via zoom breakout room technology: a case of pair programming involving students with learning disabilities. Commun. Assoc. Inform. Syst. 48:12.

Lockyer, L., Bennett, S., Agostinho, S., and Harper, B. (2008). Handbook of Research on Learning Design and Learning Objects: Issues, Applications and Technologies. Pennsylvania: IGI Global.

Manly, T. S., Leonard, L. N. K., and Riemenschneider, C. K. (2015). Academic integrity in the information age: virtues of respect and responsibility. J. Bus. Ethics 127, 579-590. doi: 10.1007/s10551-014-2060-8

Pan, G., and Seow, P.-S. (2016). Preparing accounting graduates for digital revolution: a critical review of information technology competencies and skills development. J. Educ. Bus. 91, 166-175. doi: 10.1080/08832323.2016.1145622

Papamitsiou, Z., Lunde, M., Westermoen, J., and Giannakos, M. N. (2021). "Supporting learners in a crisis context with smart self-assessment," in Radical Solutions for Education in a Crisis Context, eds D. Burgos, A. Tlili, and A. Tabacco (Singapore: Springer), 207-224. doi: 10.1007/978-981-15-7869-4_14

Pappas, I. O., Giannakos, M. N., and Mikalef, P. (2017). Investigating students' use and adoption of with-video assignments: lessons learnt for video-based open educational resources. J. Comput. Higher Educ. 29, 160-177. doi: 10.1007/ s12528-017-9132-6

Pappas, I. O., Mora, S., Jaccheri, L., and Mikalef, P. (2018). "Empowering social innovators through collaborative and experiential learning," in Proceedings of the EDUCON2018 - IEEE Global Engineering Education Conference, Tenerife.

Premlatha, K. R., and Geetha, T. V. (2015). Learning content design and learner adaptation for adaptive e-learning environment: a survey. Artif. Intell. Rev. 44, 443-465. doi: 10.1007/s10462-015-9432-z

Sheard, J., Butler, M., Falkner, K., Morgan, M., and Weerasinghe, A. (2017). "Strategies for maintaining academic integrity in first-year computing courses," in Proceedings of the 2017 ACM Conference on Innovation and Technology in Computer Science Education, (Bologna, Italy).

Smit, S., Tacke, T., Lund, S., Manyika, J., and Thiel, L. (2020). The Future of Work in Europe: Automation, Workforce Transitions, and the Shifting Geography of Employment. McKinsey Global Institute.

Topi, H., Karsten, H., Brown, S. A., Carvalho, J. A., Donnellan, B., and Shen, J. (2017). MSIS 2016 global competency model for graduate degree programs in information systems. Communications of the Association for Information Systems 18:40. doi: 10.17705/1CAIS.04018

Topi, H., Valacich, J. S., Wright, R. T., Kaiser, K. M., Nunamaker, J. F. Jr., and Sipior, J. C. (2010). "Curriculum guidelines for undergraduate degree programs in information systems," in ACM/AIS Task Force, (New York, NY: Curriculum Guidelines for Undergraduate Degree Programs in Information Systems Technical Report).

Towle, B., and Halm, M. (2005). "Designing adaptive learning environments with learning design,” in Learning Design, eds R. Koper and C. Tattersall (Berlin: Springer), 215-226. doi: 10.1007/3-540-27360-3_12

U.S. Bureau of Labor Statistics (2020). Employment Projections 2019-2029. Available online at: https://www.bls.gov/news.release/pdf/ecopro.pdf (accessed September 1, 2020).

Vesin, B., Mangaroska, K., and Giannakos, M. (2018). Learning in smart environments: user-centered design and analytics of an adaptive learning system. Smart Learn. Environ. 5:24.

Vesin, B., Mangaroska, K., and Giannakos, M. N. (2021). “Adaptive assessment and content recommendation in online programming courses: on the use of Elorating," in ACM Transactions on Computing Education (TOCE). Forthcoming.

Wang, A. I. (2015). The wear out effect of a game-based student response system. Comput. Educ. 82, 217-227. doi: 10.1016/j.compedu.2014.11.004

Wang, A. I., and Tahir, R. (2020). The effect of using Kahoot! for learning-A literature review. Comput. Educ. 149:103818. doi: 10.1016/j.compedu.2020. 103818

Zainuddin, Z., Shujahat, M., Haruna, H., and Chu, S. K. W. (2020). The role of gamified e-quizzes on student learning and engagement: an interactive gamification solution for a formative assessment system. Comput. Educ. 145:103729. doi: 10.1016/j.compedu.2019.103729

Zweben, S., and Bizot, B. (2015). CRA taulbee survey report 2014: relentless growth in undergraduate CS enrollment; doctoral degree production remains strong but no new record. Comput. Res. News 28:5.

Conflict of Interest: The authors declare that the research was conducted in the absence of any commercial or financial relationships that could be construed as a potential conflict of interest.

Copyright (c) 2021 Pappas and Giannakos. This is an open-access article distributed under the terms of the Creative Commons Attribution License (CC BY). The use, distribution or reproduction in other forums is permitted, provided the original author(s) and the copyright owner(s) are credited and that the original publication in this journal is cited, in accordance with accepted academic practice. No use, distribution or reproduction is permitted which does not comply with these terms. 